OPEN ACCESS

Edited by:

Hao Yi,

Chongqing University, China

Reviewed by:

Elif Eren Gültekin,

Selçuk University, Turkey

Yan Sunarya,

Bandung Institute of Technology,

Indonesia

*Correspondence:

P. W. Anggoro

pauluswisnuanggoro@ymail.com

p.wisnuanggoro@gmail.com

Specialty section:

This article was submitted to

Digital Manufacturing,

a section of the journal

Frontiers in Mechanical Engineering

Received: 21 October 2021 Accepted: 22 December 2021

Published: 21 February 2022

Citation:

Anggoro PW, Yuniarto T, Bawono B,

Setyohadi $D B$, Felasari $S$,

Widyanarka ODW, Tauviqirrahman M,

Jamari J and Bayuseno AP (2022)

Advanced Design and Fabrication of

Islamic Tile Ceramic Wall Tiles With

Indonesian Batik Patterns Using

Artistic CAD/CAM and $3 D$

Printing Technology.

Front. Mech. Eng 7:799086.

doi: 10.3389/fmech.2021.799086

\section{Advanced Design and Fabrication of Islamic Tile Ceramic Wall Tiles With Indonesian Batik Patterns Using Artistic CAD/CAM and 3D Printing Technology}

\author{
P. W. Anggoro ${ }^{1 *}$, T. Yuniarto ${ }^{1}$, B. Bawono ${ }^{1}$, D. B. Setyohadi ${ }^{2}$, S. Felasari ${ }^{3}$, \\ O. D. W. Widyanarka ${ }^{4}$, M. Tauviqirrahman ${ }^{5}$, J. Jamari ${ }^{5}$ and A. P. Bayuseno ${ }^{5}$
}

${ }^{1}$ Department of Industrial Engineering, Faculty of Industrial Technology, University of Atma Jaya Yogyakarta, Yogyakarta, Indonesia, ${ }^{2}$ Department of Informatics, Faculty of Industrial Technology, University of Atma Jaya Yogyakarta, Yogyakarta, Indonesia, ${ }^{3}$ Department of Architect Engineering, Faculty of Engineering, University of Atma Jaya Yogyakarta, Yogyakarta, Indonesia, ${ }^{4}$ Naruna Ceramic Studio, Salatiga, Indonesia, ${ }^{5}$ Department of Mechanical Engineering, University of Diponegoro, Semarang, Indonesia

The ceramic tile wall is a decorative element used inside restaurants, museums, hotels, aristocratic residences, and places of worship. It plays a critical role in the development of a structure with strong personality and unique qualities by providing relief patterns specific to history or era. The demand for distinctive ornamental wall ceramics that can be mass produced with precision and accuracy has been a challenge for numerous ceramic enterprises in Indonesia, which have historically relied on the skills of artistic professionals in a handmaking process. The purpose of this research was therefore to develop and apply a ceramic tile design process that integrates computer design and fabrication methods with traditional ceramic production techniques. Using the ArtCAM 2015R2 software, photos of batik and Islamic themes were effectively converted into a 2.5D computer-aided design model. Additive manufacturing technology was then used in conjunction with Objet30 Pro 3D printer to precisely produce master molds with Islamic nuances such as puzzle and floral patterns, then conventional ceramic fabrication technology was employed to produce ceramic tiles using these molds. By combining computer-aided design and rapid prototyping technologies, a variety of exact and detailed Islamic decorative ceramic wall tiles were produced with dimensional accuracies within $2.00 \mathrm{~mm}$. Furthermore, the proposed approach demonstrated a $90 \%$ reduction in designto-production time from to $10-12$ months to roughly $1-1.5$ months.

Keywords: Indonesian batik motifs, Islamic ceramic wall tiles, artistic computer-aided design/manufacturing, rapid prototyping, 3D printing

\section{INTRODUCTION}

Ceramics are clay-based materials that are commonly prepared from powders and subsequently fabricated using the sintering (firing) process. Ceramic products have long been produced in many countries, and their designs and artistic qualities are typically influenced by the local history and culture. In general, the ceramic art and design process forms clay and ceramic materials into artistic 
pottery, tableware, tiles, figurines, and other sculptures. Such products may comprise goods with motifs ranging from traditional to contemporary. Indeed, ceramic art can be found in domestic appliances, displays, and architectural trimmings. Ceramic tiles with architectural features have also been widely applied as the surfaces of interior partitions, floors, and ceilings. Furthermore, ceramic tiles are highly popular in modern architecture because of their low maintenance, resilience, and ease of cleaning, allowing them to withstand a variety environments including wet areas, dry areas, heavily used rooms, countertops, fireplaces, and tucked-away corners (Lang, 2004; Renzi, 2009).

Ceramic tiles are placed in a modular fashion as they are bonded to the wall. Such tiles may be of any shape or size, ranging from 1/4-inch mosaics to 24-by-36-foot large-format porcelains. Current ceramic tiles have evolved into new design trends that incorporate art and vibrant colors. Correspondingly, the tile surfaces may be adorned with a work of art. To make wall tiles attractive, single-color tiles have been adopted as the predominant style, in which tin-coating technologies are used to cover a large portion of the tile surface. For example, Islamic artists utilized single-color tin-glazed tiles extensively to decorate mosques and palaces from Seville in Moorish Spain to Samarkand in Central Asia. These tiles were decorated to serve a similar purpose to colored stone or marble in a mosaic (Yao, 2017).

However, the development of artistic ceramic tiles is challenging because their images encompass numerous principles such as color, pattern, and texture selection, all of which can be altered to complement the characteristics of the room in which the tiles are installed (Lang, 2004). Owing to the inherent complexity of ceramic tiles, their design requires that millions of data points be analyzed by the computer. As a result, computer-aided design (CAD) has become a vital tool in the design of contemporary ceramic art. Indeed, to practically accommodate this variability and complexity during fabrication (Renzi, 2009; Wang et al., 2014; Anggoro et al., 2015), CAD-based strategies have been proposed to create correctly detailed and precise ceramic products. Tile designers frequently use $\mathrm{CAD}$ to convert $2 \mathrm{D}$-drafted plans or images in the .jpg format into a 3D model surface or mold as needed by the customer.

The application of 3D-CAD during design and fabrication can also reduce the delivery time and decrease production costs. Currently, the 3D-CAD design technique facilitates the transition of products from physical to digital copies (mockups) and from 2D to 3D models (Ye et al., 2004; Ye et al., 2008). During the design, tooling, modeling, and simulation processes, the $3 \mathrm{D}-\mathrm{CAD}$ method involves manual as well as entirely automated digital processes (Hoffmann, 1989; Delchambre, 1997). Accordingly, new tile models can be created using digital representations of analogous copies previously stored in databanks. This allows the use of 3D search algorithms to locate product models with similar design forms and objectives (Funkhouser et al., 2003; Iyer et al., 2003; Tangelder and Veltkamp, 2008). Likewise, a new design can be strengthened by reprocessing an entire previous model or an individual previous element (Hong et al., 2006; Hou and Ramani,
2006). The availability of data in a 3D format (Funkhouser et al., 2003) has resulted in the development of $3 \mathrm{D}$ replicas into a dynamic exploration of innovative modeling and recovery methods, particularly in ceramic floor tile production.

Additionally, the CAD approach can generate $2 \mathrm{D}$ trajectories and 2.5-D prototypes of a product or element. This simplifies and accelerates the process of creating and modifying images while performing numerous design tasks (Fergiawan et al., 2020). Thus, CAD data can be utilized to easily determine the dimensions, surfaces, and masses of the objects to be fabricated. Moreover, $\mathrm{CAD}$ prototypes can undergo numerous model changes to meet demanding simulations of physical properties and functions before being converted into manufactured goods (Anggoro P. W. et al., 2019). As a result, the use of CAD offers an optimal model for product development.

Accompanying the development of CAD technology, creative computer-aided manufacturing (ArtCAM) has been introduced to provide rapid and effective manufacturing of extremely complex artistic designs (Anggoro et al., 2018; Anggoro P. et al., 2019). ArtCAM can be used for design purposes in a variety of manufacturing industries, including souvenirs, jewelry, ceramics, and component manufacturing. Additionally, it is appropriate for producing $2 \mathrm{D}$ and $2.5 \mathrm{D}$ models with a high level of feature complexity. The ArtCAM software modeling process begins by generating a $2 \mathrm{D}$ vector model from an image file. This $2 \mathrm{D}$ vector generation technique can be used to create a new design that replicates an original pattern, thereby fulfilling market demand. It has been previously demonstrated that design processes using ArtCAM can successfully produce a master set of patterns for ornate Islamic ceramic wall tiles (Chua et al., 1997a; Chua et al., 1997b; Oancea et al., 2013; Zhang et al., 2018; Anggoro P. W. et al., 2019; Han et al., 2021).

Finally, the additive manufacturing technique, often called 3D printing, has long been implemented in structural design (Bechthold et al., 2015; Bechthold, 2016). This method stems primarily from the ability to rapidly model complex components without the limitations of flat tooling rates by depositing layers of a relatively high-viscosity clay onto a fixed surface using a scaffold or another approach (Koshnevis et al., 2001). This technique has also been found suitable for the 3D manufacturing of small ceramic items (Zocca et al., 2015). Thus, comparatively small objects with complex geometries can be created using reproductive computer approaches (Bechthold et al., 2015) such as those reliant on CAD/CAM.

Various extant mosaic patterns are available as models for new ceramic tile products used as ornamentation on floors and walls in cottages, hotels, historical structures, and mosques. In arts, design, and architecture, an ornament is a decorative element that can be utilized to enhance the appearance of a particular part of a structure or object by evoking emotion or embellishing design. Ornaments can be carved from stone, wood, metal, or clay. The ornaments featured in mosques are typically based on specific Islamic ornamental motifs (Figure 1) defined by embellishments that take the shape of geometry, flowers, patterns, and calligraphy. Such Islamic geometric patterns (IGPs) have been utilized decoratively on walls, ceilings, doorways, domes, and towers for centuries (Abdullahi and Embi, 2013). Generally, IGPs 


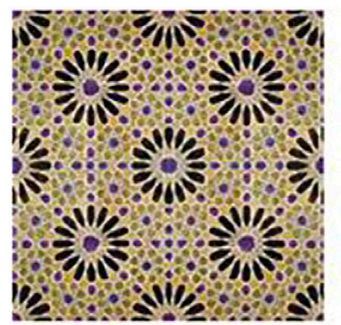

001

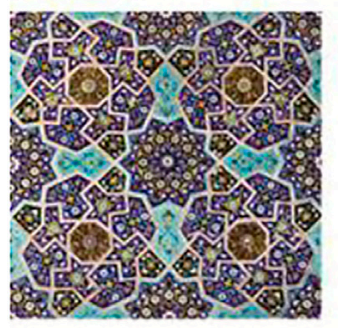

005

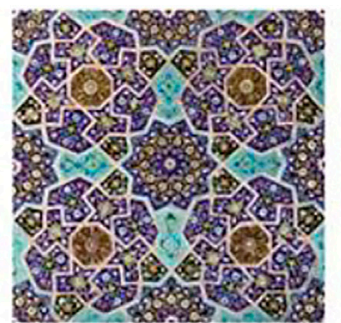

002

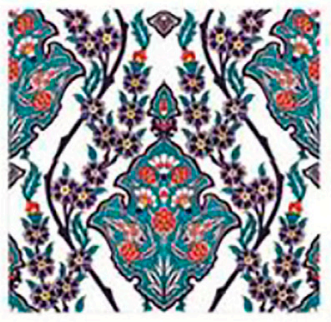

006

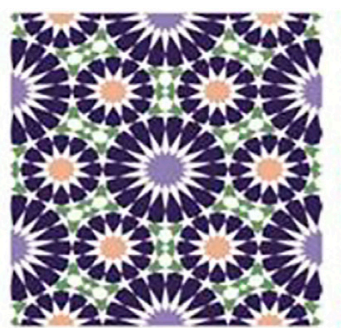

003

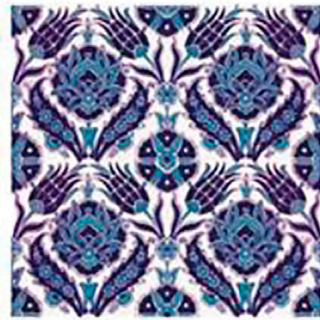

007

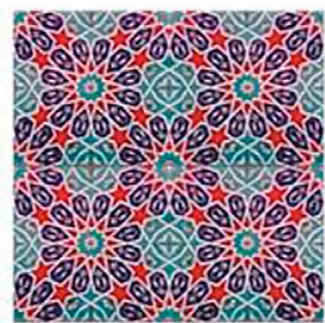

004

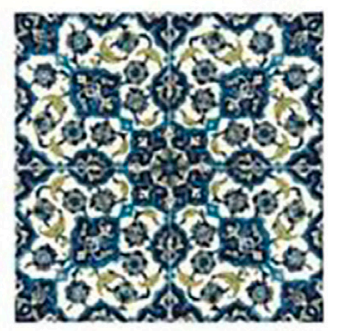

008

FIGURE 1 | Islamic geometric and floral patterns from .jpg images.

take the form of Zillij motifs, an ornamental Islamic art form that incorporated geometric elements into continuous patterns and lines that repeat and rotate their basic shapes, as illustrated in Figure 1. Of particular note, Islamic horticulture enjoyed a renaissance in the eighth century, extending from India to Northern Africa and eventually reaching Spain. Comprising an astonishingly humorous and diverse artistic character, this practice was sustained by various Islamic cultural civilizations. The warm climate of the Islamic lands and the widespread use of block construction mean that ceramics offered an attractive and appropriate form of embellishment for the interior and exterior ramparts of both sacred and secular structures. Indeed, glassy exteriors such as ceramics conserve energy and are easy to clean in a sandy environment (Yao, 2017; Anggoro et al., 2018). Symmetrical ornamentation, calligraphic tiles, floral shapes, Persian tile models, Abbasid or Seljuk slates, tile models and elegances, Timurid tiles, Il-Khnaid tiles, Safavid tiles, Iznik tiles, and Egyptian and Syrian tiles have all been discussed in great detail (Sanchez et al., 2010; Abdullahi and Embi, 2013; Anggoro et al., 2018; Taib and Rasdi, 2021).

Batik is a native Indonesian art form that can be applied as a ceramic tile design motif. The many types of batik reflect a philosophy drawn from the diverse customs of Indonesian civilizations. A batik motif can be fashioned in a variety of ways and can be created by combining outlines and forms into a single unit representing the basis of the batik pattern. Batik patterns can include human, animal, abstract, geometric, or other forms. Indeed, both IGPs and Indonesian batik motifs (IBMs) make extensive use of precise depictions of natural elements, such as flowers and trees. Furthermore, IBMs are frequently used to express social standing. Finally, batik is an inherited tradition. As a result, IBMs frequently become synonymous with the individual craftsmen who originally produced them. The ability to adopt an IBM to ceramic tiles while retaining the historical significance of Indonesian batik offers an important approach to making this cultural product more widely available. Thus, in this study, the ornamental motifs in Figure 1 were turned into wall tiles combining IGP and batik features.

Historically, the notion of traditional ceramic art in Indonesia, as well as the stages of the ceramic design and fabrication processes, relies solely on the designer's creativity and originality. Consequently, the manufacture of high-quality ceramic artwork frequently takes a long time, resulting in high prices that are unaffordable to most customers. In fact, a year is often required to develop a single type of ceramic wall tile design from the image stage to the ceramic model stage. The present design process begins with the generation of concepts, followed by the hand-drawing of sketches, then the development of $3 \mathrm{D}$ drawings and renderings to inform 3D models. Given this process, the manufacture of highly precise ceramic wall tiles can likely be improved using advanced design and fabrication based on ArtCAM and 3D printing technology. Indeed, the timeconsuming process of pattern development and model production highlights the benefits of using computational approaches to accelerate the development and production of ceramic wall tiles with unique ornamentation such as IGPs and IBMs that highlight natural beauty and flora. However, little research has been conducted on the design and fabrication stages of patterned ceramic wall tiles, and there remains a lack of relevant data in the literature describing advances in these processes.

The research issue addressed in this study was identified in the investigation of a challenge experienced by a local ceramic manufacturer in Boyolali, Central Java, regarding the production of puzzle-type ceramic wall tiles. These tiles were being manufactured manually (by hand), resulting in imprecise tiles and their inappropriate fit when assembled into a wall 
covering. In addition, this manual manufacturing process required a lengthy design time of approximately 10-12 months, as the size of the ceramic wall images created from printed photographs was inconsistent. As a result, this study investigated an advanced method for the design and manufacture of ceramic wall tiles with a flowery batik-based pattern for use in a Jakarta mosque partition. Given the intended application of these tiles, the distinguishing structures and divisions of IGPs were included in the output elaborate and decorative themes. The findings of this study are intended to contribute to the design and production of ceramic tiles with distinctive batik themes, part of Indonesia's unique national heritage.

\section{MATERIALS AND METHODS}

In this study, diverse examples of Islamic tilework were first investigated to create representative tile patterns. The researchers conducted a brainstorming session with the ceramic manufacturer's owner, design engineer, and fabrication section, resulting in the acquisition of multiple ceramic wall tile designs with IGPs (Abdullahi and Embi, 2013; Abdullahi and Embi, 2015; Taib and Rasdi, 2021) in the form of photographs in the .jpg file format. A number Islamic decorations with Indonesian geometric and batik forms, shown in Figure 1, were collected from the walls of a Jakarta mosque in 2018 and input as .jpg image files. These designs included plant and flower themes, which have long been used to decorate Islamic structures (Abdullahi and Embi, 2015; Anggoro P. et al., 2019). In general, critiques of Islamic architecture employ a descriptive and historical approach (Abdullahi and Embi, 2013; Abdullahi and Embi, 2015). The most popular plant ornamentations in this study were compared to a collection of Islamic ornaments from the most significant surviving structures. This investigation also extended chronologically from the early phases of Islam's foundation to the late 18th century, including regions ranging from West Africa to the Indian subcontinent, thereby examining the production of significant Muslim cultures and ruling dynasties. Additionally, 150 examples of well-preserved Islamic ornamentation were collected and identified chronologically and geographically through appraisal and date categorization. To determine the principles of abstract Islamic plant ornamentation, the formal characteristics of such ornamentation were investigated, including their constructive geometry, scale, and proportion; line thickness and curve type; pattern density; materials; colors; and processes. Generally, such ornamentation takes the form of Zillij motifs, an ornamental Islamic art form that consists of repeating and rotating basic shapes combined into continuous patterns and lines. Furthermore, Iznik tile, which is a magnificent demonstration of tile makers' artistry in terms of quality and intensity of color that demonstrates the improvement of design accomplished during the third quarter of the 16th century (Lang, 2004; Anggoro et al., 2018), was included as well.

Surface modeling vectors were then constructed from the eight varieties of ornamentation shown in Figure 1 by converting the .jpg photo files into master 2.5D solid models in the .stl format using the ArtCAM 2015R2 software developed by Delcam (Chua et al., 1997a; Chua et al., 1997b; Zhang et al., 2018). This software is intended for both craftspeople and engineers, and because it can produce aesthetic objects, it necessitates the combination of art, science, engineering, and technology. ArtCAM enables the rapid and easy creation of sophisticated $3 \mathrm{D}$ reliefs from $2 \mathrm{D}$ vectors or images generated by the software or imported from other CAD software. Figure $\mathbf{2 A}$ depicts the process of using ArtCAM to convert Islamic puzzle tile pattern 005 from the .jpg file format to the .stl model format. Vector lines were employed in this study to create a two-dimensional vector of each wall tile patterns via tracing, similar to previous work in making ceramic jewelry (Oancea et al., 2013; Fergiawan et al., 2020; Han et al., 2021). Figure 2B depicts the detailed stages of the Islamic puzzle tile component design and production processes using IBMs. Upon completion of the design, a master rapid prototyping (RP) model of each ceramic tile was created using the Objet30 Pro 3D printing machine (Figure 3). The RP model was then used to produce core and cavity molds for final tile production.

Figure 4 depicts the ceramic tile fabrication process employed by a local ceramic enterprise in the Salatiga district of Central Java, Indonesia, to produce IGP ceramic tiles. The final tiles (shown in Figure 5) were assembled into ceramic wall components to evaluate the accuracy of the replicated tiles. These tile components can be assembled in a manner akin to a jigsaw puzzle to make the ceramic tile wall a neat, elegant, and exact illustration. Thus, the tiles were finally assembled into specific Islamic ceramic tile puzzle walls, as shown in Figure 6A-C, then erected in the Al Huda Mosque in Jakarta, as shown in Figure 6D.

A diagram showing the research process used in this study to obtain Islamic-patterned ceramic wall tiles is presented in detail in Figure 7.

\section{RESULTS AND DISCUSSION}

In this section, the elements of the identified IGP/IBM tile patterns shown in Figure $\mathbf{1}$ are first analyzed. Then, the efficacy of the proposed application of ArtCAM to the design and fabrication of Islamic puzzle ceramic tile walls is discussed. Finally, the accuracy of the proposed design and fabrication method is demonstrated using measurements collected throughout the proposed process.

\section{Analysis of IGP and IBM}

Substantial commonalities can be observed among the IBMs in Figure 1. Indeed, the primary features of vegetative ornamentation associated with Islamic architecture are likely present based on the findings of prior studies (30). The use of IBMs was therefore considered to ascertain whether the proposed ceramic tile wall design with ornamentation bore a substantial resemblance to the adornment found in Islamic architecture, particularly in the Middle East (Figure 8), as these tile designs were intended for application in a mosque. The adequacy of this verification stage was confirmed during the vector-matrix generation stage, which was performed using the ArtCAM 2015R2 software (Figure 2). The results indicated that IGP 

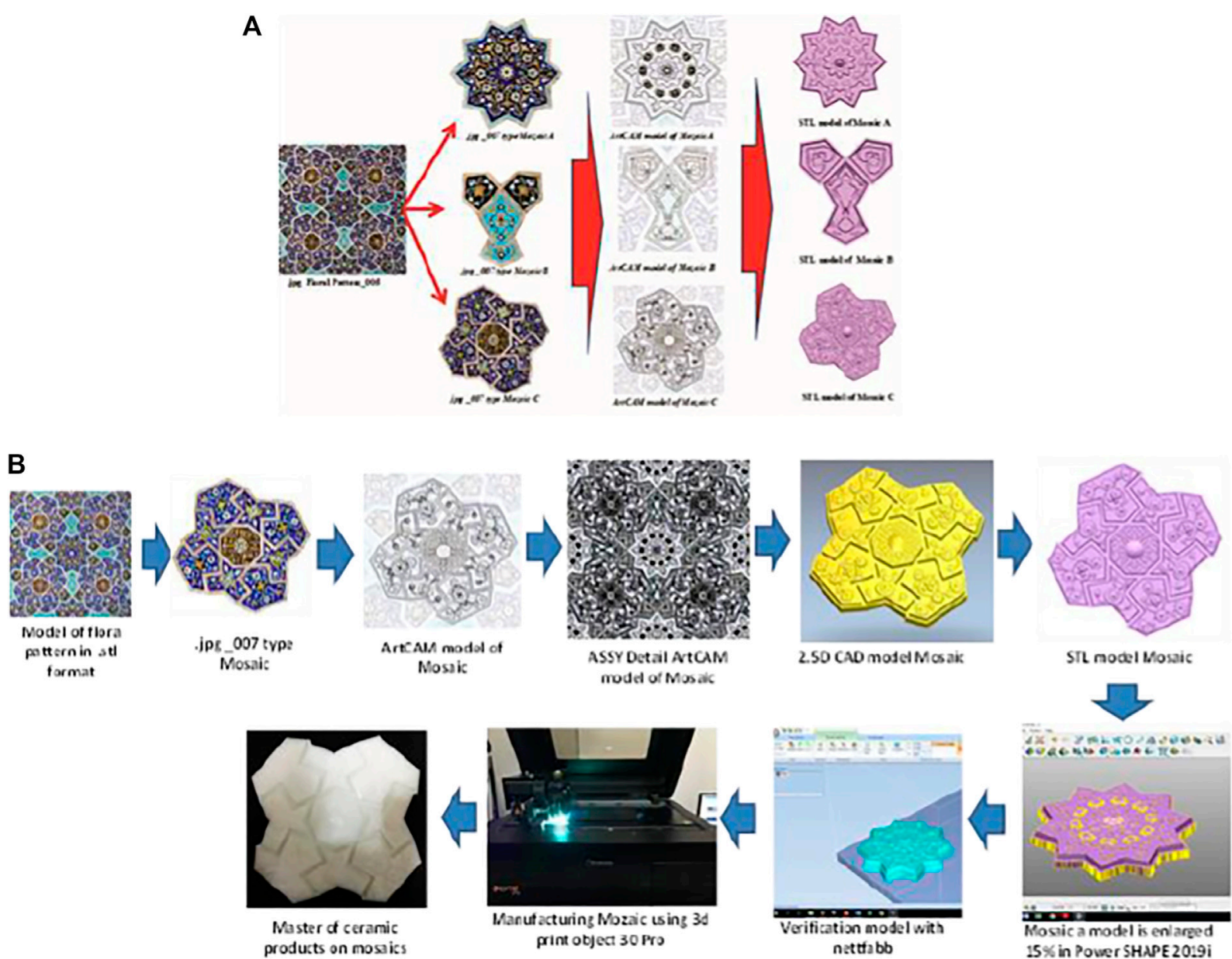

FIGURE 2 | Design process for the production of Islamic ceramic tile puzzle walls: (A) vector generation in ArtCAM 2015R2; (B) design to manufacture of master product tile wall using $3 \mathrm{D}$ printing.

serves as the foundation of types 001-005, while the Iznik tile serves as the foundation for types 006-008. Furthermore, the four IBM types 002, 005, 007, and 008 in Figure 1 specifically corresponded to the evolution of major elements of Islamic floral ornamentation (Figure 9).

Ornamentation types 001-004 in Figure 1 exhibit a concealed Islamic design that disperses mass, creates space, encloses, energizes, and shocks the human eye. Notably, geometric displays, blossoming plant structures, and enticing rationales set these patterns apart from Western craftsmanship, which is typically centered on nature and the human body. Geometry is critical to Islamic decoration, and Islamic artisans have been widely acknowledged to have accurately replicated the symmetrical principles of nature; as a result, geometric design has grown to a level of sophistication and modernism not seen previously (Figure 6) (Abdullahi and Embi, 2013; Anggoro et al., 2018). Indeed, flowers and trees have frequently been used as embellishment motifs (Figure 1), in arabesque designs, to define space, perform mindboggling tricks with color, and create a three-dimensional effect (Figures 5, 6A). Finally, pattern types 005, 007, and 008 were selected for modeling and production using the proposed method.
The link between IGP and IBM is summarized in Figures 8, 9. This tight relationship also supported the tile maker's request that the researchers adapt the IBM into a 2.5 creative CAD design model (Figures 2, 10) with the same qualities as an IGP. As a result, the principles of Islamic ornamentation may be made practical for the design and manufacture of wall tiles set on the exterior walls of places of worship, such as mosques or prayer rooms (Figure 6B).

\section{Application of ArtCAM to Islamic Puzzle Ceramic Tile Walls}

The collected photographs were reproduced in the .jpg format for tile pattern types 005, 007, and 008 in Figure 1. Then, vector files in the .stl format were converted into $2.5 \mathrm{D}$ CAD ceramic tile puzzle wall models with IGP ornaments and constructed using ArtCAM 2015R2, Power SHAPE 2016, and Autodesk Netfabb basic (see Figure 2). The results of the ArtCAM design and production process are presented in the form of RP product components that serve as the master patterns for the molding process (Figure 3). These master RP models were then sent to the 
A
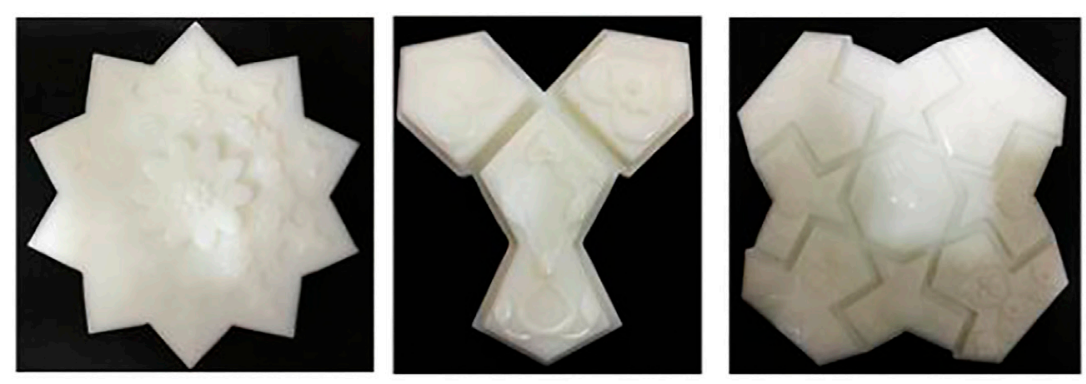

B
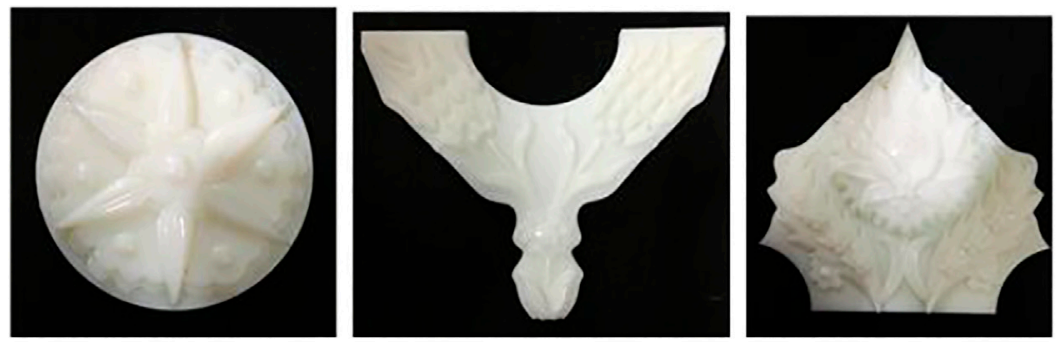

C
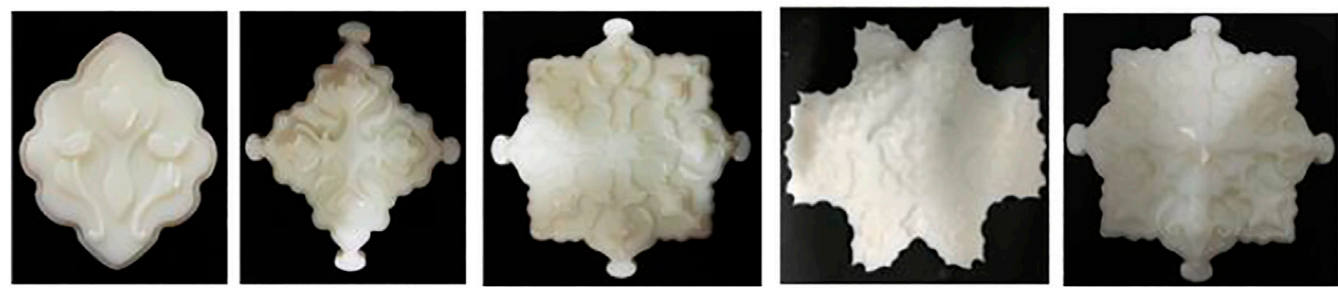

FIGURE 3 | Master molds of ceramic tiles in mosaics: (A) IGP/IBM tiles (pattern 005); (B)

B) Iznik tiles (pattern 007);

C) Safavid tiles (pattern 008).

ceramic plant, where they were used to create ceramic core and cavity molds for subsequent tile fabrication (Figure 4).

The IGP vector conversion of the designs in the photos in the .jpg format was partitioned into several patterns using the tracing operation in ArtCAM. Through this process, the primary image in the photograph was isolated into a collection of notable components that were prepared for production in a $2.5 \mathrm{D}$ demonstration (Figure 2). For example, the tiles for pattern 007 were dubbed Safavid tiles and divided into five components: the cloud, edge, corner, center, and white ornament, shown in Figure 10. By using the tracing operation provided in ArtCAM 2015R2, these five Safavid tile components were then generated as vectors for the $2.5 \mathrm{D}$ solid artistic model in the .stl format using the process detailed in Figure 11.

The measurements, surface quality, and strength shown in this image were first checked using the Netfabb software. Then, the master pattern models were printed using additional material fabrication innovations provided with the Objet30 Pro 3D printer (Sanz et al., 2012; Oancea et al., 2013; Wang et al., 2014; Anggoro et al., 2021). The printed model was then used to create core and cavity molds of the ceramic tile form that produced raw tiles composed entirely of extraordinarily white clay. This model was increased in volume by approximately $15 \%$ to account for shrinkage during the firing process, as depicted in Figure 3.

\section{Quality Measurement of Ceramic Tiles}

Figure 4 illustrates the stages of development for each ceramic tile design, which includes casting, coating, and firing procedures at a local ceramic production factory. After establishing the model for each component constituting the given ceramic tile wall pattern, a $100 \mathrm{~cm} \times 100 \mathrm{~cm}$ sample of each ceramic tile pattern was obtained (see Figure 5) as shown in Figure 6A-C. The origins of all ceramics are perplexing. These ornate Islamic wall tile patterns were then successfully placed on the walls of Jakarta's Al Huda Mosque with excellent precision and accuracy (Figure 6D). The design and manufacture of these ceramics resulted in the creation of ceramic tiles (Chua et al., 1997a; Chua et al., 1997b; Sanchez et al., 2010; Sanz et al., 2012; Oancea et al., 2013; Anggoro et al., 2015; Anggoro et al., 2018; Anggoro et al., 2021). Note that the dimensional accuracy of the ceramic tile plan, determined by comparing the initial design dimensions with measurements of the printed model and final tiles, is crucial. The geometric quality of the completed ceramic wall tiles was therefore confirmed for the components of three different patterns $(005,007$, and 008) to determine how much dimensional variation existed between the final product, the ArtCAM model images, and the master molds (Figure 3) to illustrate the viability of the change in fabrication strategy 


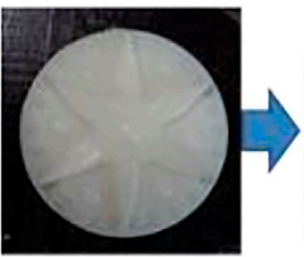

Master model

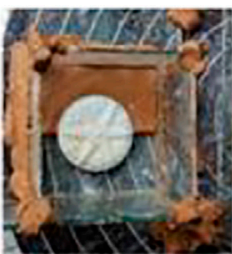

Mold making

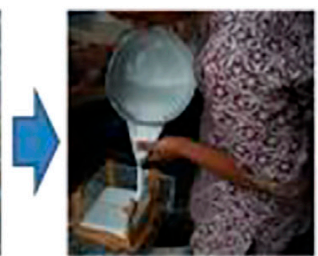

pouring clay material for mold models

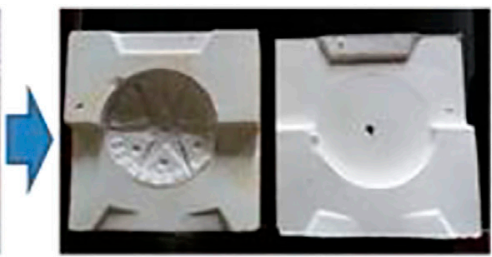

core $\&$ cavity tile mosaic
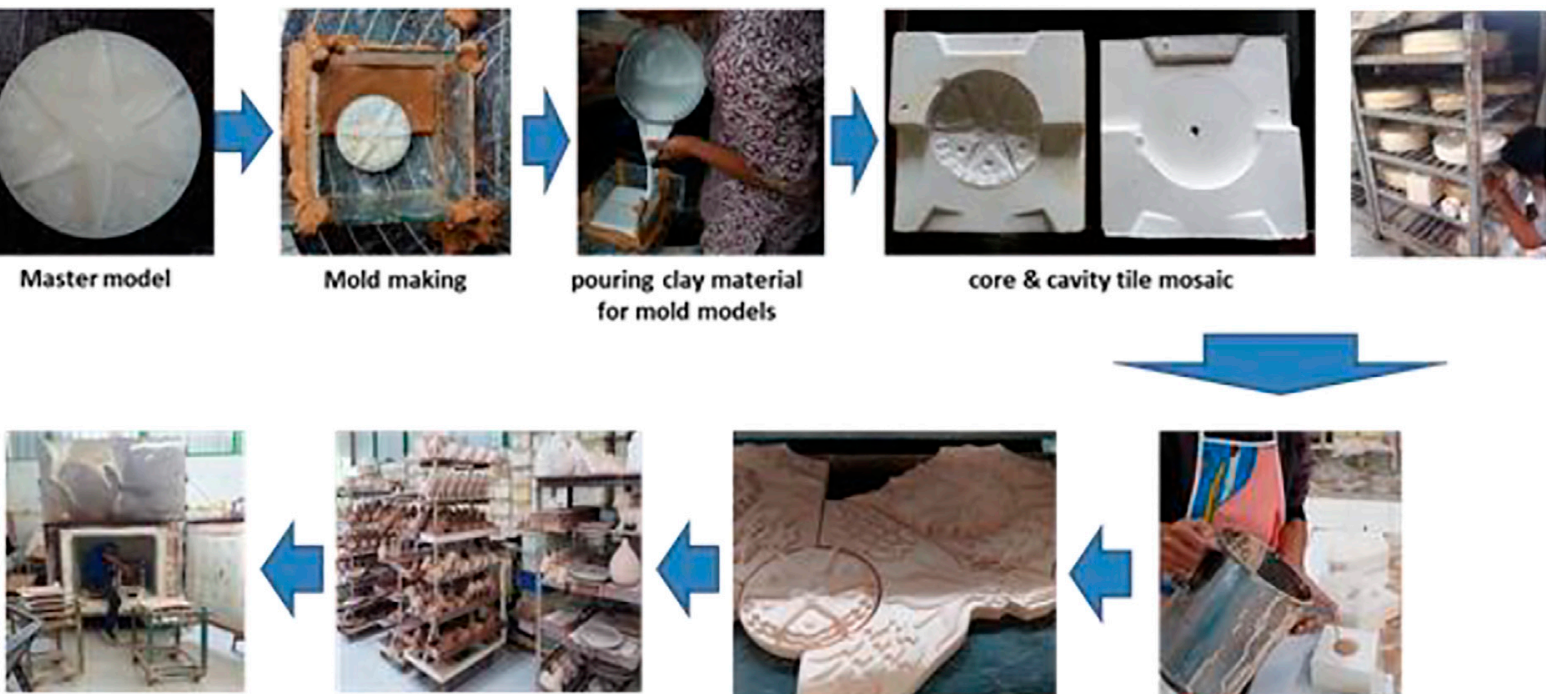

First burning (biscuit)

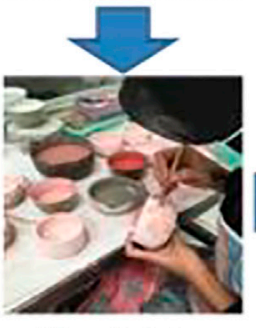

Manual glazing

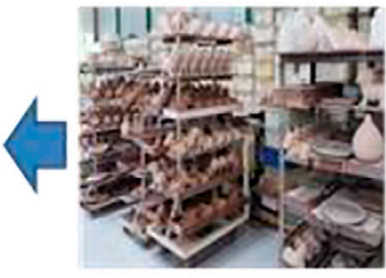

Clay drying

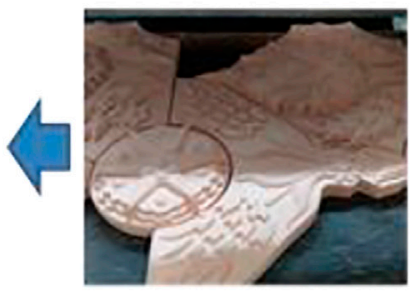

Pile of tile before burn

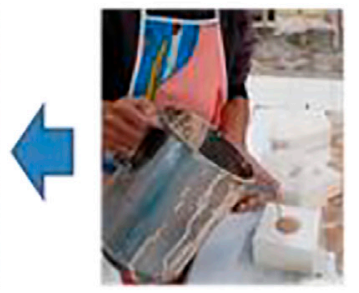

casting
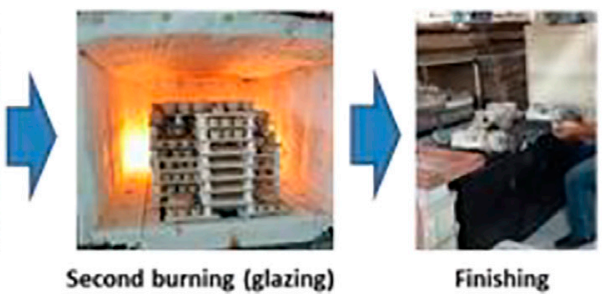

FIGURE 4 | General stages of IGP/IBM ceramic tile fabrication in an Indonesian ceramics factory.

A
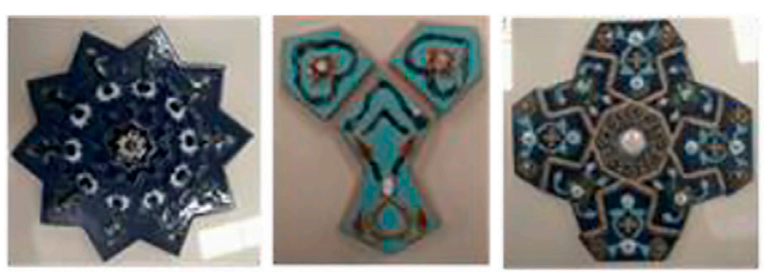

B
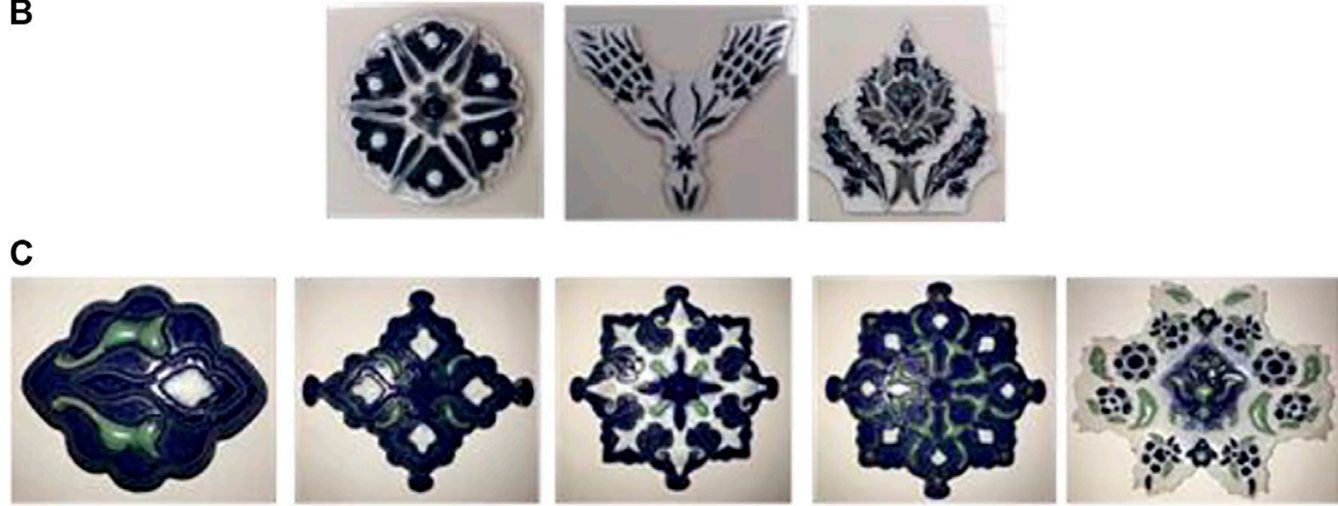

FIGURE 5 | Produced tile elements for (A) IGP/IBM tiles (pattern 005); (B) Iznik tiles (pattern 007); (C) Safavid tiles (pattern 008). 

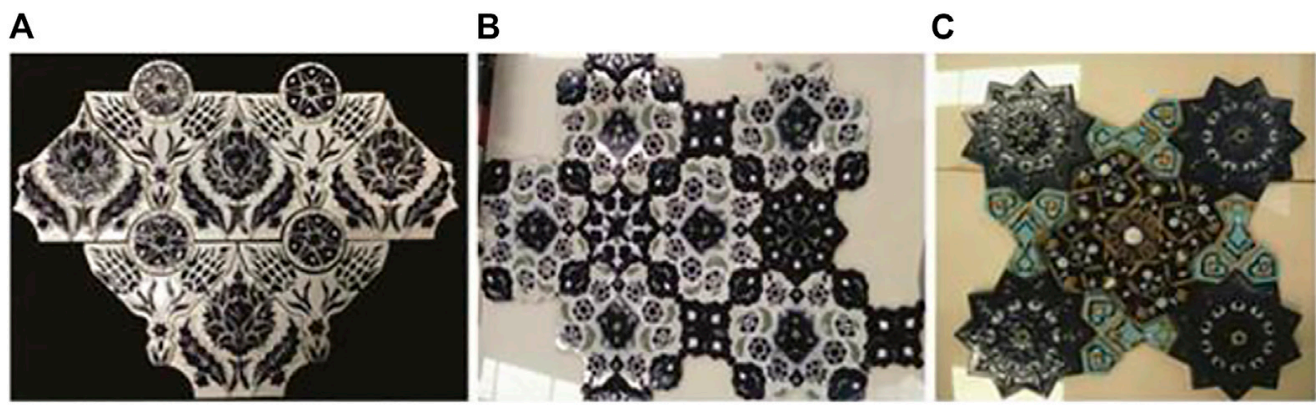

D

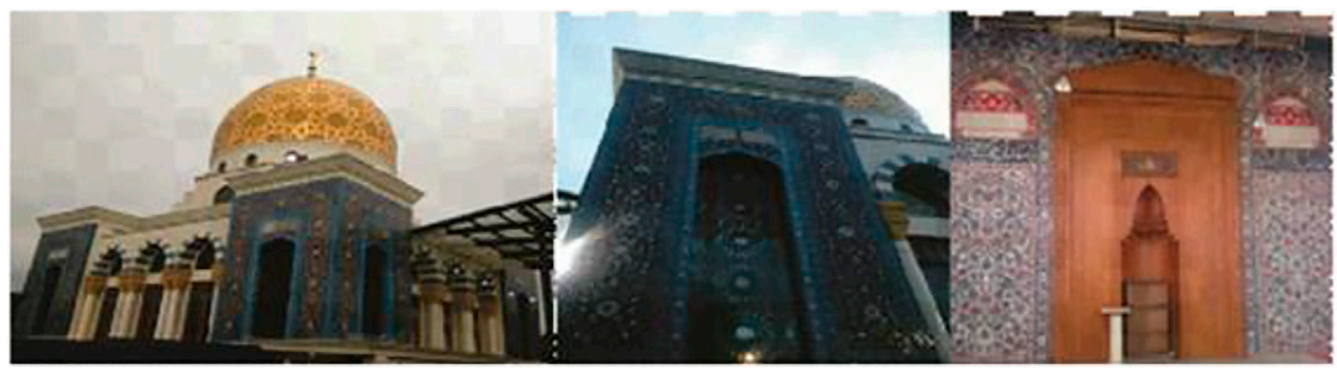

FIGURE 6| Assembled Islamic ceramic tiles: (A) Iznik tiles (pattern 007); (B) Safavid tiles (pattern 008); (C) IGP/IBM tiles (pattern 005); and (D) assembled tile walls on the Al Huda Mosque (Anggoro P. W. et al., 2019).

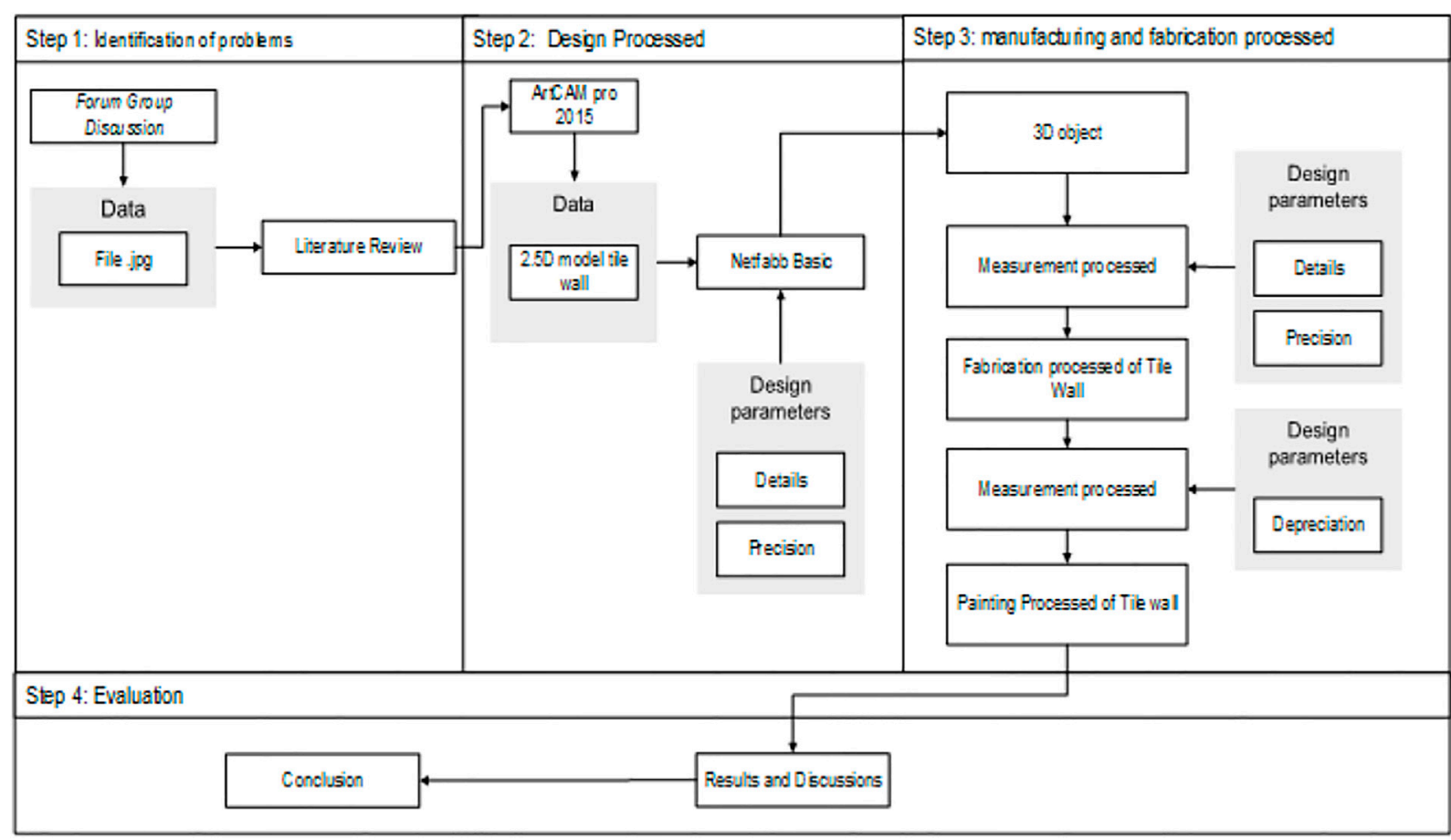

FIGURE 7 | Flow chart of the CARE System applied to design and manufacture Islamic ceramic wall tiles in this study.

from the use of a $2 \mathrm{D}$ to a 2.5D standard (RP) using the 2.00$\mathrm{mm}$ tolerance provided by the ceramics manufacturer. Measurement points were identified through brainstorming with the creative group to highlight focal points, with each measurement selected to require a minimum of additional measurements (Figure 12). Measuring these dimensions 


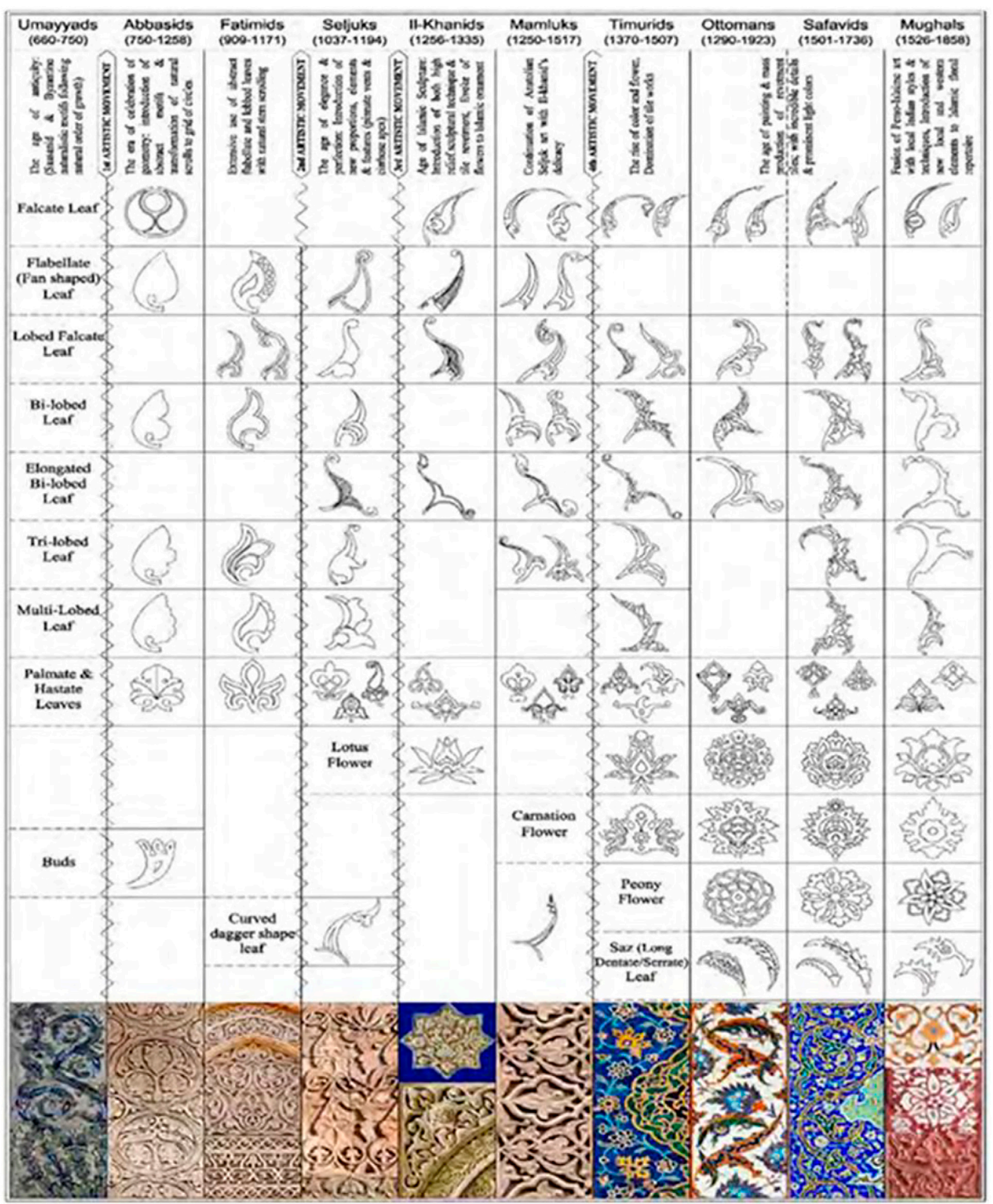

FIGURE 8 | Evolution of the main elements of Islamic floral ornamentation.

established the appropriate angle size for the master of the print pattern to produce a high-quality mold. Later, the measurement of the Safavid tile design was modified to also include two angles, namely, $80^{\circ}$ and $85^{\circ}$. The chosen perspectives was the product of brainstorming with the research and development department at the ceramic factory. 


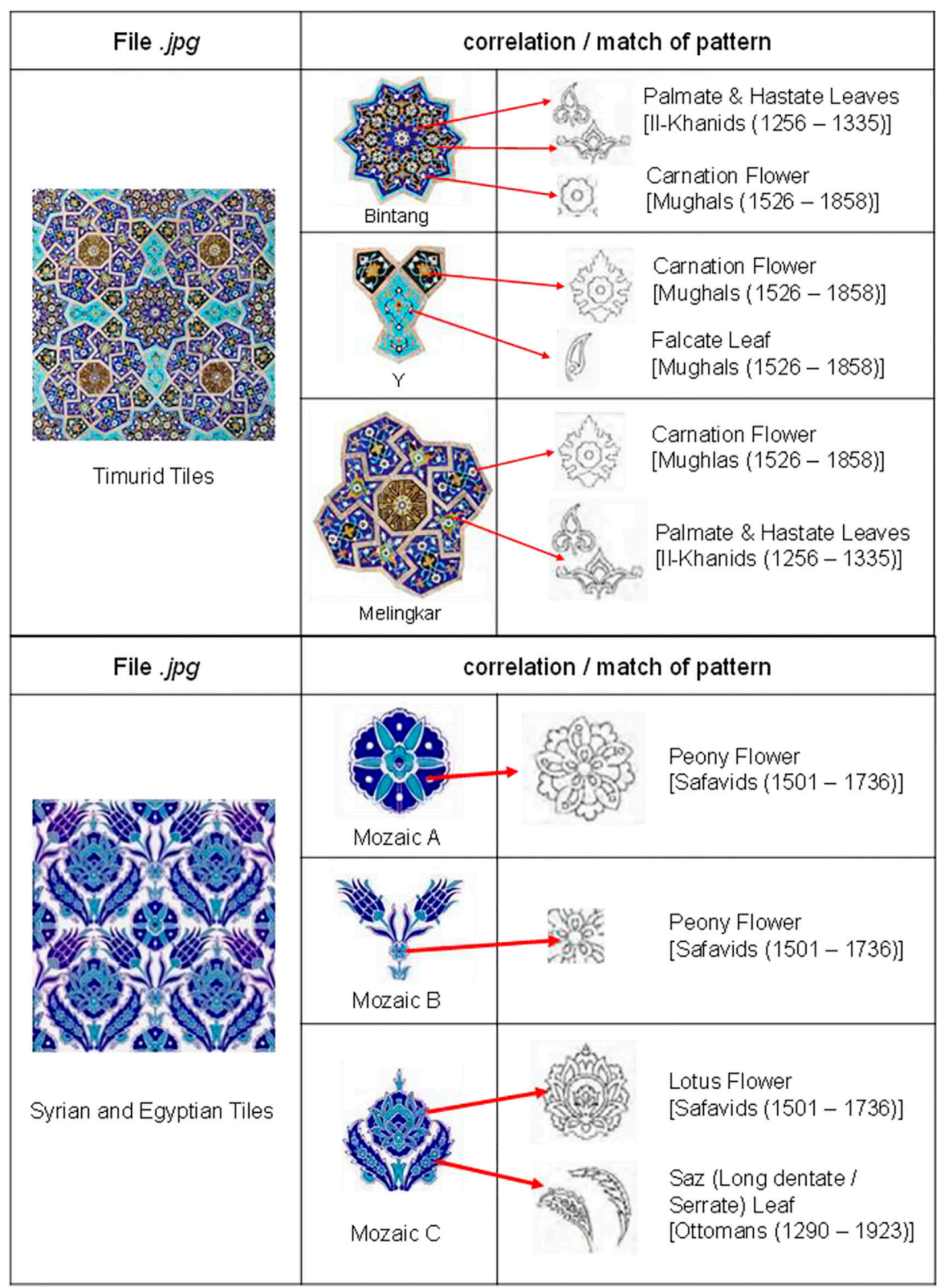

FIGURE 9 | (Last Table 4) Similarities between the customer images and main elements of Islamic floral ornamentation.

The kiln firing of ceramics causes clay to shrink as its water content evaporates, resulting in a decrease in size; the degree of this decrease is referred to as shrinkage. As a result, the dimensions of the tiles must be increased according to specific shrinkage value of the clay as well as the kiln firing technique utilized during manufacturing (Anggoro et al., 2021). The 


\section{A

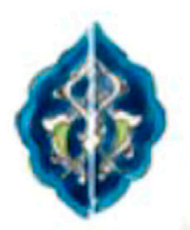

B

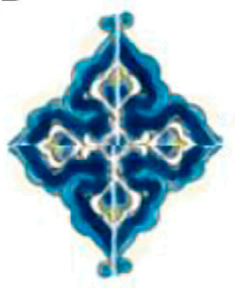

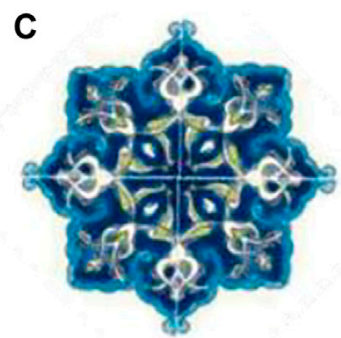

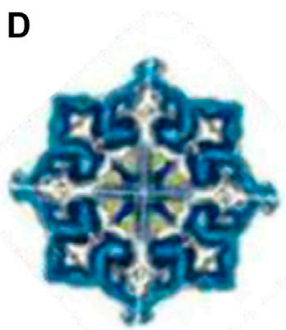

E

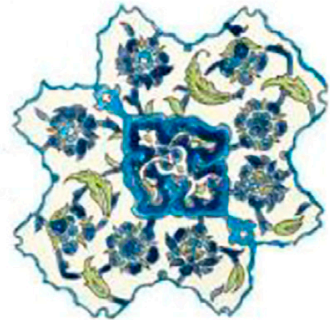

FIGURE 10 | Components of Safavid puzzle tiles: (A) cloud; (B) side; (C) corner; (D) center; (E) white ornament.
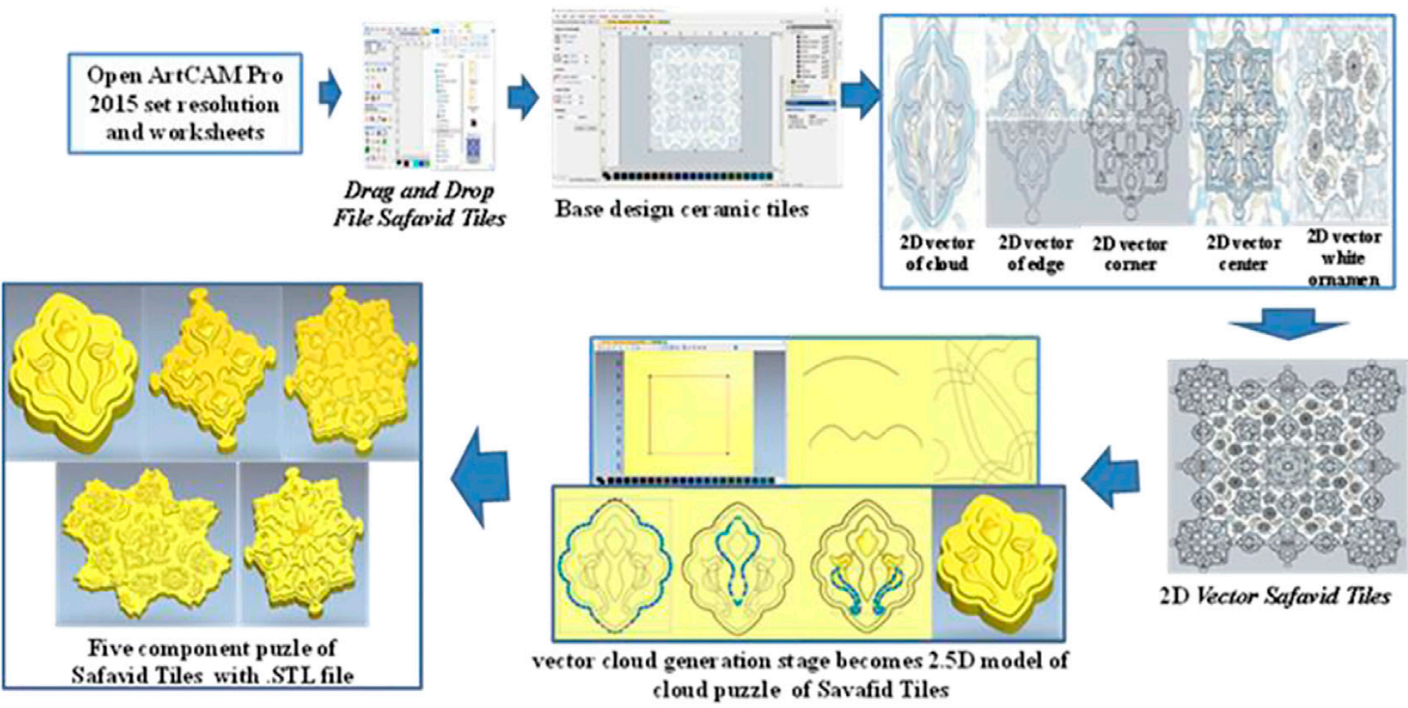

2D Vector Safavid Tiles

FIGURE 11 | Stages of vector generation from .jpg file to .stl file in ArtCAM Pro2015.

dimensions acquired after shrinkage (the final dimensions of the ceramic tile) should thus be close to $15 \%$ smaller than those of the master model without shrinkage.

The final dimensions of the clay models and ceramic wall tiles are shown in Supplementary Table S1, in which the yellow cells highlight instances of shrinkage in excess of $15 \%$, with the blue cells indicating the corresponding dimensions of the RP model and the green cells indicating the size of the actual tiles. When the shrinkage exceeded $15 \%$, measurement validation was carried out with the results presented in Table 1. In this table, the green cells indicate when the tile size measurements were at the control limit or lower limit. The black bold numbers indicate when the tile size was within the limits, and the red bold numbers indicate when the tile size was at the lower limit and therefore included in the unsafe category. However, in all cases, factory quality control decided to continue the tile fabrication process because the tolerances were within the range approved by the manufacturer.

Several equations were utilized in this study using the data in Supplementary Table S1 to demonstrate how the final size of the ceramic tile is within the tolerance range set jointly by the research team and engineers from the ceramic plant. The following simple mathematical equations were used to quantify the dimensional accuracy of the resulting tiles:

$$
\begin{aligned}
& E_{1}=b-a \\
& E_{2}=c-b \\
& E_{3}=d-a
\end{aligned}
$$

where $E_{1}, E_{2}$, and $E_{3}$ denote the deviations between measurements $(\mathrm{mm}) ; a$ is the measurement of a component on the RP model (mm); $b$ is the measurement of the same component on the core and cavity mold $(\mathrm{mm}) ; c$ is the measurement of the same component on the raw clay tile prior to firing $(\mathrm{mm})$; and $d$ is the measurement of the same component on the final ceramic tile $(\mathrm{mm})$.

The overall shrinkage was determined as follows:

$$
\text { Calculated shrinkage }=\frac{\text { Clay model }- \text { Ceramic tile }}{\text { Clay model }} \times 100 \%
$$

where calculated shrinkage is the percent shrinkage of the raw clay model dimensions produced from the core and cavity molds relative to the final ceramic tile dimensions. 


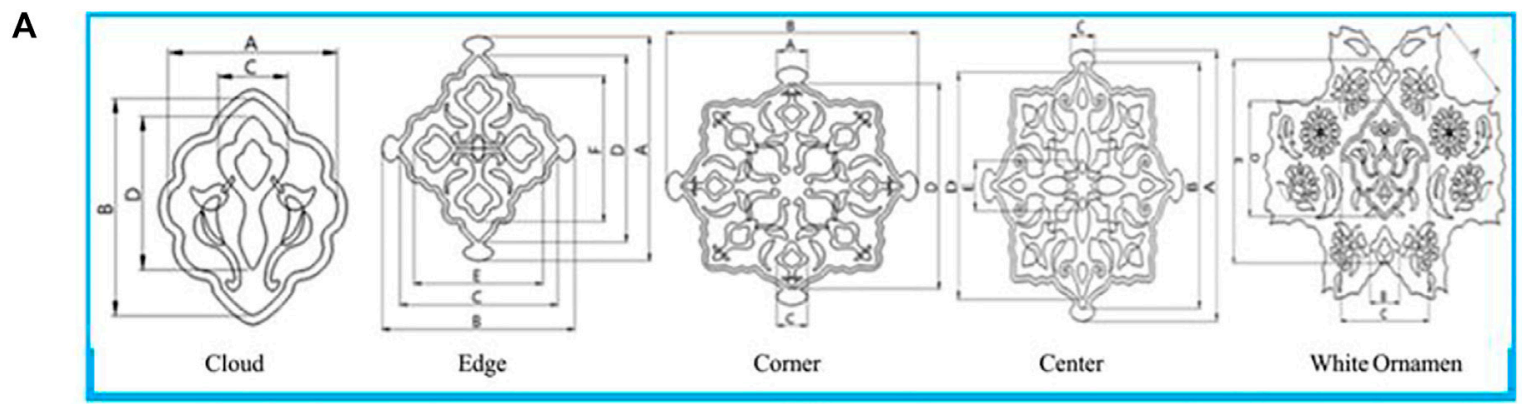

B

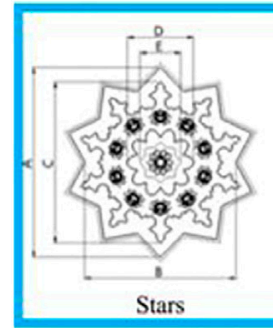

C

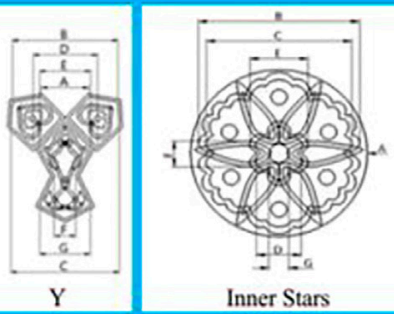

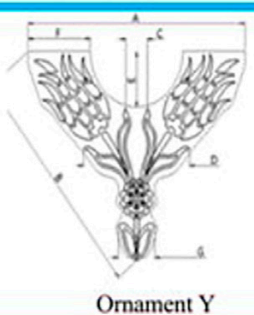

Ornament $\mathrm{Y}$

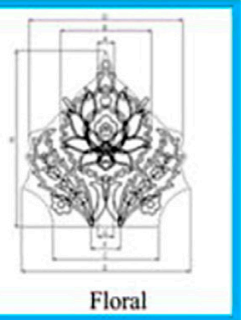

FIGURE 12 | Measurements of Islamic ceramic wall tiles: (A) Safavid tiles; (B) IGP/IBM tiles; (C) Iznik tiles.

TABLE 1 | Validation of measurements and established tolerances of wall tiles with shrinkage greater than $15 \%$.

\begin{tabular}{|c|c|c|c|c|c|c|c|}
\hline $\begin{array}{l}\text { Part of } \\
\text { pattern }\end{array}$ & Measure & $\begin{array}{c}\text { Raw clay } \\
\text { model (mm) }\end{array}$ & $\begin{array}{c}\text { With } \\
15 \% \\
\text { shrinkage }(\mathrm{mm})\end{array}$ & $\begin{array}{c}\text { Lower } \\
\text { limit }(-2 \mathrm{~mm})\end{array}$ & $\begin{array}{c}\text { Final ceramic } \\
\text { tile } \\
\text { (control limit) }\end{array}$ & $\begin{array}{c}\text { Upper } \\
\text { limit (+2 } \mathrm{mm})\end{array}$ & Decision \\
\hline 007 & $\mathrm{D}$ & 14.57 & 12.38 & 10.38 & 12.10 & 14.38 & Safe to fabricate \\
\hline \multirow[t]{2}{*}{ Mosaic A } & Height & 20.10 & 17.09 & 15.09 & 16.37 & 19.09 & Safe to fabricate \\
\hline & & 20.10 & 17.09 & 15.09 & 16.53 & 19.09 & Safe to fabricate \\
\hline 007 & $\mathrm{D}$ & 143.12 & 121.65 & 119.03 & 119.65 & 123.65 & Safe to fabricate \\
\hline \multirow[t]{3}{*}{ Mosaic C } & & 143.33 & 121.83 & 119.83 & 120.63 & 123.83 & Safe to fabricate \\
\hline & $E$ & 157.04 & 133.48 & 130.32 & 131.48 & 135.48 & Unsafe but accepted \\
\hline & & 157.10 & 133.54 & 130.68 & 131.54 & 135.64 & Unsafe but accepted \\
\hline \multirow[t]{2}{*}{ Size } & Height & 17.38 & 15.00 & 12.77 & 14.77 & 16.77 & Safe to fabricate \\
\hline & & 17.48 & 20.18 & 12.96 & 14.60 & 16.96 & Safe to fabricate \\
\hline 008 & $\mathrm{~B}$ & 136.67 & 116.17 & 114.17 & 116.17 & 118.17 & Safe to fabricate \\
\hline \multicolumn{8}{|l|}{ Corner } \\
\hline 008 & $E$ & 22.54 & 19.15 & 17.15 & 18.25 & 21.15 & Safe to fabricate \\
\hline
\end{tabular}

Center

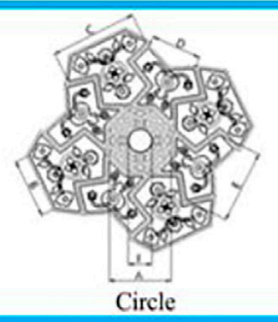

The meaning of the value marked in bold + this value indicates the actual geometry of the finished ceramic and has experienced a shrinkage of $15 \%$ so that the fabrication process is declared safe.

A shrinkage limit of $11 \%-15 \%$ was determined by the authors using a variety of ceramic engineering resources (Chua et al., 1997a; Oancea et al., 2013; Fergiawan et al., 2020; Anggoro et al., 2021) that calculated the percent shrinkage of clays utilized in the ceramics industry. The clay used to create the Islamic puzzle tile walls in this study was bone China type with a $15 \%$ shrinkage (Fergiawan et al., 2020; Anggoro et al., 2021). This value was then used to denote the limits of the selected measurements according to the shrinkage value; after the firing process was completed, the selected dimensions were reduced by $15 \%$ with a tolerance of
$2.00 \mathrm{~mm}$. In this study, the geometries measured during the modeling process were defined as the prototype model sizes (for the RP model and core/cavity molds) and final product sizes (for the raw, unfired clay tile and final ceramic tile). The prototype model size was determined using data collected at predefined locations and measured by researchers using a 0.01 $\mathrm{mm}$ caliper. The final product size was determined in a similar fashion. The results are reported in Supplementary Table S1 for the dimensions defined in Figure 12. The results show that the variation was within $1.00 \mathrm{~mm}$ for the $80^{\circ}$ and $85^{\circ}$ plan variants, 
while the maximum standard for ceramic production plants is $2.00 \mathrm{~mm}$

Eqs 1-4 were used to generate the shrinkage data corresponding to the measured lengths, and these results are also presented in Supplementary Table S1. The verification of several dimensions that exhibited shrinkage values greater than $15 \%$ is presented in Table $\mathbf{1}$. The final results show that shrinkage values greater than $15 \%$ were present at point $\mathrm{E}$ on mosaic $\mathrm{C}$ that did not meet the standard, as the final dimension of the ceramic tile was smaller than the lower limit $(130.32 \mathrm{~mm}<131.48 \mathrm{~mm})$ and $(130.68 \mathrm{~mm}<131.54 \mathrm{~mm})$.

The results of this study indicate that the shrinkage of ceramic wall tiles varies depending on the measurement. According to Supplementary Table S1, the shrinkage of the three types of ceramic tiles evaluated (patterns 005, 007, and 008) was typically less than $15 \%$. Ceramics with a shrinkage greater than $15 \%$ were subjected to verification tests with tolerances of 1-2 mm. After verification of the seven measurements on each mosaic type, only two on mosaic $\mathrm{C}$ were deemed unsafe to proceed to fabrication at the factory, but the ceramic manufacturer accepted these dimensions nonetheless and continued to fabricate the tiles for installation.

Thus, the size deviation between the $2.5 \mathrm{D}$ model, RP master, raw ceramic tile, and final ceramic tile was found to meet the established standards, indicating that the 3D-printed master model could be confidently used as a shape design for the investigated wall tiles. Furthermore, the results indicate that the proposed design and fabrication methods decreased the time-to-production from $10-12$ to $1-1.5$ months, a $90 \%$ reduction. This accuracy is maintained throughout the manufacturing and installation of the tile arrangement, meeting the requirements of the ceramic factory and resulting in a final product that satisfies the legal and aesthetic requirements of the Masjid Al Huda in Jakarta.

\section{CONCLUSION}

In this study, the stages of realizing a unique ceramic wall tile design combining traditional IGPs with IBMs using ArtCAM 2015 and 3D-printing technology were demonstrated within the local Indonesian porcelain ceramics industry. To do so, the integration of computer fabrication skills with traditional ceramic production techniques was realized. The ceramic tiles with geometric and floral designs exhibited the desired surface forms and dimensional fit established in 2.5D CAD and reflected in the $3 \mathrm{D}$ modeling design models. Furthermore, the approach developed in this study can reduce the design-to-fabrication time by up to $90 \%$.

In future work, collaborative technologies such as 3D CAD, CAM, and computer numerical control can be utilized in conjunction with conventional ceramic technology to design and create ceramic tableware and tiles with a variety of textures, patterns, and shapes. This approach is expected to address design and manufacturing issues that have plagued ceramics producers in Indonesia, who have a long history of generating bespoke ceramic tiles.

\section{DATA AVAILABILITY STATEMENT}

The original contributions presented in the study are included in the article/Supplementary Material; further inquiries can be directed to the corresponding author.

\section{AUTHOR CONTRIBUTIONS}

PWA is the main author of this research. He did all the design, manufacturing, data analysis, and writing of the paper. TY and SF designed and manufactured $3 \mathrm{D}$ print of ceramic wall tiles. MT, $\mathrm{BB}$, and ODWW contributed to collecting data measurement and fabricating ceramic wall tiles at industry. DBS and JJ analyzed and interpreted the data. APB contributed the concept and wrote the paper with PWA. All authors contributed to the article and approved the submitted version.

\section{FUNDING}

This research was funded by the Directorate of the Research and Community Service, Directorate General of Research and Development Strengthening, Ministry of Research, Technology and Higher Education Fiscal Year 2021, Grant Number: 2817/ E4.1/KK.04.05/2021 and Grant Number: 3586/E3/SPMK.07/KL/ 2021.

\section{ACKNOWLEDGMENTS}

The authors appreciate Prof. Ir. Yoyong Arfiadi, M.Eng., Ph.D., Rektor Universitas Atma Jaya Yogyakarta; Ririn Diar Astanti, D.Eng., Head of Department Industrial Engineering, Faculty of Industrial Technology, University of Atma Jaya Yogyakarta; Universitas Diponegoro Semarang; PT Gyan Kreatif Indonesia; PT Nuanza Porcelain Indonesia; and PT. Hankook Delcam Indonesia for providing full support in the form of infrastructures such as CAM, CAD, and RE needed during the design, development, and writing of this research work.

\section{SUPPLEMENTARY MATERIAL}

The Supplementary Material for this article can be found online at: https://www.frontiersin.org/articles/10.3389/fmech.2021.799086/ full\#supplementary-material

Supplementary Table 1 | Measurement results and dimensional discrepancy between the 2.5D .stl ArtCAM model and the stages of ceramic tile production for types 007 and 008. 


\section{REFERENCES}

Abdullahi, Y., and Embi, M. R. B. (2013). Evolution of Islamic Geometric Patterns. Front. Architectural Res. 2 (2), 243-251. doi:10.1016/j.foar.2013.03.002

Abdullahi, Y., and Rashid Embi, M. (2015). Evolution of Abstract Vegetal Ornaments in Islamic Architecture. ArchNet-IJAR 91, 31-49. doi:10.26687/ archnet-ijar.v9i1.558

Anggoro, P. W., Bawono, B., and Sujatmiko, I. (2015). Reverse Engineering Technology in Redesign Process Ceramics: Application for CNN Plate. Proced. Manufacturing 4, 521-527. doi:10.1016/j.promfg.2015.11.071

Anggoro, P. W., Tan Wijaya, A. R., Yuniarto, T., Bayuseno, A. P., Jamari, J., Tauviqirrahman, M., et al. (2021). Reverse Engineering from 3D Mesh to Ceramic Product in the Form of Miranda Kerr Tea for One Teapot in PT Doulton Indonesia. Cogent Eng. 8 (1), 1981522. doi:10.1080/23311916.2021.1981522

Anggoro, P. W., Tauviqirrahman, M., Jamari, J., Bayuseno, A. P., Bawono, B., and Avelina, M. M. (2018). Computer-aided Reverse Engineering System in the Design and Production of Orthotic Insole Shoes for Patients with Diabetes. Cogent Eng. 5 (1), 1470916. doi:10.1080/23311916.2018.1470916

Anggoro, P. W., Tauviqirrahman, M., Jamari, J., Bayuseno, A. P., Wibowo, J., and Saputro, Y. D. (2019a). Optimal Design and Fabrication of Shoe Lasts for Ankle Foot Orthotics for Patients with Diabetes. Int. J. Manuf. Mater. Mech. Eng. 9 (2), 62-80. doi:10.4018/ijmmme.2019040104

Anggoro, P. W., Yuniarto, T., Tauviqirrahman, M., Jamari, J., Bayuseno, A. P., Purwanto, K. B., et al. (2019b). "Puzzle Islamic Floral Patterns Product Tiles for Wall and Ceiling to Decorate of Al Huda Mosque Indonesia-Design, Manufacturing, and Fabrication [Conference Presentation]," in Proceedings of the 6th International Conference and Exhibition on Sustainable Energy and Advanced Materials, ICE-SEAM 2019, Surakarta, Indonesia.

Bechthold, M., Kane, A., and King, N. (2015). "Ceramic Material Systems," in Ceramic Material Systems: In Architecture and Interior Design (Basel: Birkhäuser). doi:10.1515/9783038210245

Bechthold, M. (2016). Prototipos Cerámicos - Diseño, Computación Y Fabricación Digital. Inf. Constr. 68, 167-554. doi:10.3989/ic.15.170.m15

Chua, C. K., Gay, R., and Hoheisel, W. (1997a). Computer Aided Decoration of Ceramic Tableware. Part I: 3-D Decoration. Comput. Graphics 21 (5), 641-653. PII: SOO97-8493(97)00041-1. doi:10.1016/s0097-8493(97)00041-1

Chua, C. K., Gay, R., and Hoheisel, W. (1997b). Computer Aided Decoration of Ceramic Tableware. Part II: Rapid Tooling. Comput. Graphics 21 (5), 655-672. PII: SOO97-8493(97)00042-3. doi:10.1016/s0097-8493(97)00042-3

Delchambre, A. (1997). CAD Method for Industrial Assembly - Concurrent Design of Products, Equipment, and Control Systems. Chichester: John Wiley \& Sons.

Fergiawan, P. K., Anggoro, P. W., Yuniarto, T., Purwanto, K. B., and Widyanarka, O. K. W. (2020). "Ceramic Jewelry with Texture and Ornament Islamic Pattern and Batik Indonesia - Design, Manufacturing, and Fabrication [Conference Presentation]," in Proceedings of the 6th International Conference and Exhibition on Sustainable Energy and Advanced Materials, ICE-SEAM 2019, Surakarta, Indonesia.

Funkhouser, T., Min, P., Kazhdan, M., Chen, J., Halderman, A., Dobkin, D., et al. (2003). A Search Engine for 3D Models. ACM Trans. Graph. 22 (1), 83-105. doi:10.1145/588272.588279

Han, J., Rong, M., Jiang, H., Liu, H., and Shen, S. (2021). Vectorized Indoor Surface Reconstruction from 3D Point Cloud with Multistep 2D Optimization. ISPRS J. Photogrammetry Remote Sensing 177, 57-74. doi:10.1016/j.isprsjprs.2021.04.019

Hoffmann, C. M. (1989). Geometric and Solid Modeling: An Introduction. San Mateo: Morgan Kaufmann.

Hong, T., Lee, K., and Kim, S. (2006). Similarity Comparison of Mechanical Parts to Reuse Existing Designs. Computer-Aided Des. 38 (9), 973-984. doi:10.1016/j.cad.2006. 05.004

Hou, S., and Ramani, K. (2006). “Sketch-based 3D Engineering Part Class Browsing and Retrieval," in EUROGRAPHICS Workshop on Sketch-Based Interfaces and Modeling. Editors T. Stahovich and M.C. Sousa (The Eurographics Association), 131-138.
Iyer, N., Kalyanaraman, Y., Lou, K., Jayanti, S., and Ramani, K. (2003). “A Reconfigurable, Intelligent 3D Engineering Shape Search System Part I: Shape Representation," in Proceedings of ASME DETC' 03, 23rd Computers and Information in Engineering (CIE) Conference, Chicago, Illinois, USA, 89-98.

Khoshnevis, B., Bukkapatnam, S., Kwon, H., and Saito, J. (2001). Experimental Investigation of Contour Crafting Using Ceramics Materials. Rapid Prototyping J. 7 (1), 32-42. doi:10.1108/13552540110365144

Lang, G. (2004). 1000 Tiles: Ten Centuries of Decorative Ceramic. Chronicle Books LLC. 0-8118-4235-5.

Oancea, G., Ivan, N., and Pescaru, R. (2013). Computer-aided Reverse Engineering System Used for Customized Products. Acad. J. Manuf. Eng. 11 (4), 30-35.

Renzi, J. (20092009). The Art of Tile: Designing with Time-Honoured and New Tiles. 1st ed. New York: Clarkson Potter Publisher.

Sánchez, E., García-Ten, J., Sanz, V., and Moreno, A. (2010). Porcelain Tile: Almost 30 Years of Steady Scientific-Technological Evolution. Ceramics Int. 36 (3), 831-845. doi:10.1016/j.ceramint.2009.11.016

Sanz, V., Reig, Y., Feliu, C., Bautista, Y., Ribes, C., and Edwards, M. (2012). Technical Evolution of Ceramic Tile Printing. J. Imaging Sci. Technol. 56 (5), 50402-50411. doi:10.2352/J.ImagingSci.Technol.12.56.5.050402\#: :text=doi\% 3A10.2352/j.imagingsci.technol

Taib, M. Z. M., and Rasdi, M. T. (2021). Islamic Architecture Evolution: Perception and Behaviour. Proced. - Soc. Behav. Sci. 49, 293-303.

Tangelder, J. W. H., and Veltkamp, R. C. (2008). A Survey of Content Based 3D Shape Retrieval Methods. Multimed. Tools Appl. 39 (3), 441-471. doi:10.1007/ s11042-007-0181-0

Wang, A.-h., Sai, S.-t., and Liu, Y.-m. (2014). The High Computer Technology Application Study about the Daily-Use Ceramic Products Design. IERI Proced. 10, 184-189. doi:10.1016/j.ieri.2014.09.075

Yao, J. G. (2017). “Application of Computer-Aided Design in Ceramic Art Design [Conference Presentation]," in 2017 International Conference on Manufacturing Construction and Energy Engineering (MCEE 2017), Hong Kong, 252-256.

Ye, X., Liu, H., Chen, L., Chen, Z., Pan, X., and Zhang, S. (2008). Reverse Innovative Design - an Integrated Product Design Methodology. Computer-Aided Des. 40 (7), 812-827. doi:10.1016/j.cad.2007.07.006

Ye, X., Peng, W., Chen, Z., and Cai, Y.-Y. (2004). Today's Students, Tomorrow's Engineers: an Industrial Perspective on CAD Education. Computer-Aided Des. 3614, 1451-1460. doi:10.1016/j.cad.2003.11.006

Zhang, Y.-W., Chen, Y., Liu, H., Ji, Z., and Zhang, C. (2018). Modeling Chinese Calligraphy Reliefs from One Image. Comput. Graphics 70, 300-306. doi:10. 1016/j.cag.2017.07.022

Zocca, A., Colombo, P., Gomes, C. M., and Günster, J. (2015). Additive Manufacturing of Ceramics: Issues, Potentialities, and Opportunities. J. Am. Ceram. Soc. 98 (7), 1983-2001. doi:10.1111/jace.13700

Conflict of Interest: The authors declare that the research was conducted in the absence of any commercial or financial relationships that could be construed as a potential conflict of interest.

Publisher's Note: All claims expressed in this article are solely those of the authors and do not necessarily represent those of their affiliated organizations, or those of the publisher, the editors and the reviewers. Any product that may be evaluated in this article, or claim that may be made by its manufacturer, is not guaranteed or endorsed by the publisher.

Copyright (c) 2022 Anggoro, Yuniarto, Bawono, Setyohadi, Felasari, Widyanarka, Tauviqirrahman, Jamari and Bayuseno. This is an open-access article distributed under the terms of the Creative Commons Attribution License (CC BY). The use, distribution or reproduction in other forums is permitted, provided the original author(s) and the copyright owner(s) are credited and that the original publication in this journal is cited, in accordance with accepted academic practice. No use, distribution or reproduction is permitted which does not comply with these terms. 